\title{
Pengetahuan, Sikap dan Ketrampilan Wanita Tani dalam Pengelolaan Sampah di Wilayah Pesisir Kelurahan Srengsem
}

\section{Knowledge, Attitudes and Skills of Women Farmer in Waste Management in the Coastal Areas of Srengsem Village.}

\author{
Oleh: \\ Yuli Safitri ${ }^{1 *}$, Kordiyana K. Rangga ${ }^{1}$, Indah Listiana ${ }^{1}$ \\ ${ }^{1}$ Program Studi Penyuluhan Pertanuan, Fakultas Pertanian, Universitas Lampung. Jl. Sumantri Brojonegoro \\ 1, Bandar Lampung, 35145, Lampung, Indonesia \\ *email: safitriyuli710@gmail.com
}

Received: March 03, 2021; Revised: March 23, 2021; Accepted June 07, 2021

\begin{abstract}
ABSTRAK
Tujuan dari penelitian ini adalah untuk mengetahui tingkat pengetahuan masyarakat pesisir dalam pengelolaan sampah, mengetahui tingkat sikap masyarakat pesisir dalam pengelolaan sampah dan mengetahui tingkat keterampilan masyarakat pesisir dalam pengelolaan sampah. Penelitian ini dilakukan di Kelurahan Srengsem, Kecamatan Panjang, Bandar Lampung. Pengambilan data pada penelitian ini dilakukan pada bulan Oktober - November 2020. Responden adalah 40 wanita tani yang mengikuti di KWT Kenanga. Penelitian ini menggunakan metode survei dengan pendekatan deskriptif kuantitatif. Hasil penelitian menunjukkan bahwa tingkat pengetahuan dan sikap masyarakat pesisir dalam pengelolaan sampah tergolong tinggi akan tetapi belum didukung oleh tindakan atau keterampilan nyata artinya masyarakat sudah melakukan pengurangan dan penanganan sampah seperti mengolah limbah menjadi media tanam secara sederhana dan menampung sampah dalam satu wadah agar tidak tertebaran, akan tetapi masih belum menerapkan secara penuh pengelolaan Reduce, Reuse dan Recycle
\end{abstract}

Keywords: Pengetahuan; Sikap; Keterampilan, Pengelolaan Sampah

\begin{abstract}
The purpose of this study was to determine the level of knowledge of coastal communities in waste management, to determine the level of attitudes of coastal communities in waste management and to determine the level of skills of coastal communities in waste management. This research was conducted in Srengsem Village, Panjang District, Bandar Lampung. Data collection in this study was conducted in October-November 2020. Respondents were 40 female farmers who participated in KWT Kenanga. This study used a survey method with a quantitative descriptive approach. The results from this research are the level of knowledge and attitudes of coastal communities in waste management was classified as high but not yet supported by concrete actions or skills, meaning that the community had made waste reduction and handling such as simply processing waste into planting media and accommodating waste in one container so that it would not be scattered. however, they have not fully implemented the Reduce, Reuse and Recycle management
\end{abstract}

Keywords: Knowledge, attitudes, skills, waste management

\section{PENDAHULUAN}

Di era kemjuan teknologi saat ini, manusia selalu berupaya dalam memenuhi kebutuhan hidupnya dengan cara mengelola lingkungan. Proses pengelolaan lingkungan memiliki dampak positif dan negatif. Dampak positif pengelolaan lingkungan antara lain terpenuhinya kebutuhan hidup manusia, mendorong pembangunan nasional, 
mengembangkan teknologi informasi, membuka wawasan dan pengetahuan yang baru serta meningkatkan devisa negara, sedangkan dampak negatifnya yaitu persediaan sumberdaya alam yang semakin berkurang, degradasi tanah, pencemaran lingkungan dan dampak terparah yang dialami saat ini adalah limbah yang berlebih. Limbah merupakan sisa dari proses produksi industri maupun rumah tangga yang keberadaannya mampu menurunkan kualitas lingkungan dan Limbah padat hasil aktivitas manusia biasa disebut dengan sampah (Abdurrahman, 2008).

Bandar Lampung merupakan kota penyumbang sampah peringkat ketiga di Sumatera berdasarkan data Badan Pusat Statistik (BPS) tahun 2019. volume sampah di Kota Bandar Lampung pada tahun 2017 berjumlah $\quad 1.020 \quad \mathrm{~m}^{3} /$ hari kemudian meningkat menjadi $1.080 \mathrm{~m}^{3}$ pada tahun 2018. Perkiraan produksi itu tidak diimbangi dengan volume pengangkutan sampah ke Tempat Pembuangan Akhir (TPA) dengan jumlah $850 \mathrm{~m}^{3} /$ hari pada tahun 2017, dan 900 $\mathrm{m}^{3} /$ hari pada tahun 2018. Selisih antara produksi dengan volume sampah terangkut sebesar 170--180 m³/hari merupakan jumlah sampah yang tersebar bebas di lingkungan masyarakat.

Sampah yang tersebar bebas di lingkungan masyarakat mendapatkan perlakukan yang beragam, salah satunya dengan membuang sampah ke aliran sungai yang mengakibatkan penyumbatan dan sampah yang terbawa aliran menimbulkan penumpukan di muara pesisir. Salah satu wilayah Pesisir Bandar Lampung yang mengalami dampak buruk akibat sampah yaitu masyarakat Pesisir Kelurahan Srengsem, Kecamatan Panjang, Kota Bandar Lampung.

Pencemaran yang terjadi di Kota Bandar Lampung membuat pemerintah mengambil langkah untuk membuat peraturan tentang pengelolaan sampah. Peraturan Daerah Kota Bandar Lampung Nomor 5 tahun 2015 tentang pengelolaan sampah, menjelaskan sistem pengelolaan sampah domestik atau rumah tangga pada pasal 20 dan 22 yang menyebutkan "pengelolaan sampah rumah tangga dan sejenisnya terdiri atas pengurangan sampah dan penangan sampah.

Oleh karena itu, penting untuk mengetahui perilaku masyarakat pesisir dalam pengelolaan sampah. Perilaku individu adalah segala aktivitas dan tindakan manusia yang memiliki luasan yang sangat luas meliputi kegiatan yang dapat ditinjau secara langsung maupun tidak secara langsung (Notoatmodjo, 2011). Komponen pembentuk perilaku terdiri atas pengetahuan, sikap dan keterampilan (Gerungan, 2004). Pengetahuan adalah hasil dari penginderaan individu terhadap sesuatu objek hingga individu menjadi tentang objek tersebut. Seseorang tidak akan mungkin mampu mengambil sebuah sikap, tindakan atau keputusan tanpa memiliki pengetahuan yang mendalam pula. Menurut Notoatmodjo (2011) sikap atau biasa dikenal dalam istilah attitude merupakan respon atau reaksi seseorang yang sifatnya masih tertutup belum secara nyata dilakukan dalam hal tindakan. Sedangkan keterampilan (skill) adalah segala aktivitas manusia yang memerlukan praktek atau dapat diartikan sebagai implikasi nyata dari perilaku manusia (Megantoro, 2015. Tujuan dari penelitian ini : (1) Mengetahui tingkat pengetahuan wanita tani dalam pengelolaan sampah. (2) Mengetahui tingkat sikap wanita tani dalam pengelolaan sampah Mengetahui tingkat keterampilan wanita tani dalam pengelolaan sampah.

\section{METODE PENELITIAN}

\section{Lokasi dan Waktu Penlitian}

Penelitian ini dilakukan di Kelurahan Srengsem, Kota Bandar Lampung, Lampung, Indonesia. Waktu penelitian ini dilakukan pada bulan Oktober hingga Novemeber 2020. Kelurahan Srengsem merupakan salah satu wilayah di Pesisir Kota Bandar Lampung yang mengalami dampak penumpukan sampah akibat terbawa arus laut dan aliran sungai yang bermuara di pesisir. 


\section{Metode Penelitian}

Metode yang digunakan dalam penelitian ini adalah penelitian survei dengan pendekatan deskriptif kuantitatif. Pengambil- an data dilakukan dengan metode wawancara menggunakan kuesioner. Total sampel dalam penelitian ini adalah 40 responden dengan teknik purposive sampling untuk seluruh anggota Kelompok Wanita Tani (KWT). Kenanga.

Penelitian ini menggunakan data primer dan data sekunder. Data primer yaitu data yang diperoleh dengan wawancara langsung. Data sekunder merupakan data yang diambil dari data-data yang telah tercatat atau memang sudah tersedia, seperti perpustakaan, laporan, buku, jurnal, artikel, surat kabar, dokumen-dokumen, dan peraturan seperti Perda Kota Bandar Lampung Nomor 15 Tahun 2015 tentang Pengelolaan Sampah, Data Kelurahan Srengsem dan Data Statistik.

\section{Analisis Data}

Analisis statistik deskriptif dilaksanakan melalui beberapa tahapan:

a) Penyajian data variabel pengetahuan, sikap dan keterampilan dengan metode tabulasi

b) Penentuan kecenderungan nilai responden untuk masing-masing variabel yang dikelom-pokkan ke dalam 3 (tiga) kelas kriteria masing-masing adalah: (1) rendah, (2) sedang dan (3) tinggi. interval kelas ditentukan dengan rumus sebagai berikut:

Interval kelas $=\quad \frac{\text { nilai tertinggi-nilaiterendah }}{k i a s i f i k a s i}$

Komponen pengelolaan sampah dalam penelitian ini dilihat menurut Perda Kota Bandar Lampung Nomor 15 Tahun 2015 tentang Pengelolaan Sampah, yang terdiri dari pengurangan dan penanganan.

a) Pengurangan sampah adalah upaya meminimalisir jumlah sampah atau mengurangi jumlah produksi sampah yang dihasilkan. Upaya yang lebih spesifik dalam pengurangan sampah ini adalah kegiatan 3R (Reduce, Reuse, dan Recycle).

b) Penanganan sampah upaya menanggulangi keberadaan sampah disekitar masyarakat khusunya di tingkat rumah tangga. Upaya penanganan sampah yang terdiri dari kegiatan pewadahan dan pemilahan, pengumpulan, serta pengangkutan.

\section{HASIL DAN PEMBAHASAN}

\section{Karakteristik Responden}

\section{Umur Responden}

Umur adalah kurun waktu yang menunjukkan keberadaan suatu makhluk hidup ataupun benda. Umur responden sebagian besar termasuk dalam kategori muda dengan rata-rata 42 tahun. Hal tersebut menunjukkan bahwa umur responden termasuk pada umur produktif.

\section{Tingkat Pendidikan Responden}

Pendidikan merupakan faktor yang akan menentukan seseorang dalam berpola pikir dan mencari keputusan. sebagian besar dari responden memiliki pendidikan pada tingkat Sekolah Menengah Atas (SMA) dan Sekolah Menengah Pertama (SMP). Hal ini menunjukkan bahwa sebagian besar responden sudah memiliki pengalaman dalam mengenyam pendidikan yang cukup lama, sehingga responden dikategorikan sudah cukup mumpuni dalam menyerap informasi serta teknologi baru. Menurut Listiana (2017) menyatakan bahwa tingkat pendidikan sesorang dapat mempengaruhi kemampuan individu dalam melakukan usaha.

\section{Jumlah Tanggungan Responden}

Jumlah tanggungan dalam rumah tangga merupakan jumlah anggota keluarga yaitu terdiri dari istri, anak, serta orang lain yang ikut tinggal dalam satu rumah yang menjadi tanggungan kepala keluarga. Sebagian besar jumlah tanggungan keluarga 
anggota KWT termasuk ke dalam klasifikasi sedang dengan rata-rata jumlah tanggungan keluarga 3 jiwa. Jumlah tanggungan yang sebagian besar masuk ke dalam kategori sedang dikarenakan beberapa anggota keluarga lain yang sudah tidak tinggal bersama lagi.

\section{Pengetahuan Responden dalam Pengelolaan Sampah}

Pengetahuan adalah segala hal yang diketahui oleh manusia, sehingga seorang individu mampu memilih hal yang benar ataupun yang salah (Teng, 2017). . Pengetahuan dalam pengelolaan sampah dalam penelitian ini meliputi indikator pengetahuan dalam pengurangan dan penanganan.

Tabel 1.

Tingkat pengetahuan wanita tani dalam pengelolaan sampah.

\begin{tabular}{|c|c|c|c|c|}
\hline \multirow{2}{*}{$\begin{array}{c}\text { Indikator } \\
\text { Pengetahuan }\end{array}$} & \multirow{2}{*}{$\begin{array}{l}\text { Klasifi- } \\
\text { kasi }\end{array}$} & \multirow{2}{*}{$\begin{array}{c}\text { Interval } \\
\text { kelas } \\
\text { (skor) }\end{array}$} & \multicolumn{2}{|c|}{ Anggota KWT } \\
\hline & & & Jumlah & $(\%)$ \\
\hline \multirow[t]{3}{*}{ Pengurangan } & Rendah & $16-21$ & 5 & 12,50 \\
\hline & Sedang & $22-26$ & 4 & 10,00 \\
\hline & Tinggi & $27-32$ & 31 & 77,50 \\
\hline Rata-rata & & & & 27,05 \\
\hline \multirow[t]{3}{*}{ Penanganan } & Rendah & $14-18$ & 0 & 00,00 \\
\hline & Sedang & $19-23$ & 21 & 52,50 \\
\hline & Tinggi & $24-28$ & 19 & 47,50 \\
\hline Rata-rata & & & & 23,3 \\
\hline
\end{tabular}

Berdasarkan Tabel 1 tingkat pengetahuan sebagian besar responden dalam pengelolaan sampah pada indikator pengurangan masuk ke dalam kategori tinggi dengan persentase sebesar 77,50 persen. Indikator penanganan berada ditingkat sedang dengan persentase sebesar 52,50 persen. Masyarakat pesisir Kelurahan Srengsem mengetahui bahwa beberapa barang yang sudah tidak terpakai dapat digunakan kembali menjadi fungsi yang berbeda dengan perlakuan tertentu, seperti menggunakan botol minum bekas air mineral menjadi botol minyak goreng isi ulang. Selain itu, masyarakat juga mengetahui bahwa sampah yang sudah tidak dapat terdaur ulang harus mendapatkan penanganan yang baik untuk sampai pada pembuangan akhir, seperti mengumpulkannya dalam satu wadah agar tidak bertebaran bebas di lingkungan yang dapat mengganggu kenyamanan lingkungan sekitar, akan tetapi dalam pengetahuan pemilahan sampah masyarakat belum diketahui secara penuh. Kondisi tersebut mengakibatkan kurangnya kesadaran wanita tani dalam melakukan pemilahan sampah yang sebenarnya merupakan bagian yang terpenting dlam proses pengelolaan sampah. Hal tersebut sejalan dengan pernyataan Setyowati dan Mulasari (2013) yang menyatakan bahwa pengetahuan masyarakat dalam kegiatan pengelolaan sampah berdampak pada kesadarannya untuk melakukan pengelolaan sampah itu sendiri.

Tingkat pengetahuan masyarakat yang tinggi tentang pengelolaan sampah didapatkan melalui pendidikan formal maupun informal di kalangan masyarakat, dan adanya kemudahan bertukar informasi seperti melalui iklan layanan masyarakat elekronik maupun sosial media saat ini memudahkan masyarakat untuk mendapatkan pengetahuan. Selain itu peningkatan pengetahuan juga dapat dilakukan melalui kegiatan penyuluhan dan pemberdayaan masyarakat, seperti yang dilakukan pada KWT Kenangan ini dimana, wanita tani yang tergabung dalam program Kawasan Rumah Pangan Lestari (KRPL), walaupun tujuan utama dalam program ini adalah peningkatan pemanfaatan pekarangan untuk memenuhi kebutuhan pangan dan gizi keluarga, namun dalam pelaksanaannya pengetahuan dalam mengelola sumberdaya lokal seperti limbah rumah tangga menjadi faktor pendukung dalam pelaksanaan program. Oleh karena itu upaya peningkatan kegiatan pendidikan sangat diperlukan untuk mening-katkan pengetahuan masyarakat. Hal tersebut sejalan dengan pernyataan Rangga, dkk (2020) yang menyebutkan bahwa penyluhan dan pemberdayaan masyarakat 
mampu meningkat- kan pengetahuan dan perilakunya menjadi lebih dinamis rasional.

\section{Sikap Responden dalam Pengelolaan Sampah}

Sikap atau attitude merupakan wujud pandangan seseorang antara suka/tidak suka atau setuju/tidak setuju terhadap suatu objek atau situasi tertentu. Sikap juga mengacu pada perasaan yang timbulkan terhadap suatau fenomen (Gusti dkk, 2015). Pandangan responden dalam penelitian kali ini untuk menilai kegiatan pengelolaan sampah yang seperti seharusnya yaitu kegiatan penanganan dan pengurangan

Tabel 2.

Tingkat sikap wanita tani dalam pengelolaan sampah

\begin{tabular}{lccccc}
\hline \multirow{2}{*}{$\begin{array}{c}\text { Indikator } \\
\text { Sikap }\end{array}$} & \multirow{2}{*}{$\begin{array}{c}\text { Klasifika } \\
\text { si }\end{array}$} & $\begin{array}{c}\text { Interval } \\
\text { kelas } \\
\text { (skor) }\end{array}$ & & \multicolumn{2}{c}{ Anggota KWT } \\
\cline { 5 - 6 } & & Jumlah & $(\%)$ \\
\hline Pengurangan & Rendah & $16-32$ & & 00,00 \\
& Sedang & $33-49$ & & 15 & 37,50 \\
& Tinggi & $50-64$ & & 25 & 62,50 \\
\hline Rata-rata & & & & 50,38 \\
\hline Penanganan & Rendah & $14-28$ & & 0 & 00,00 \\
& Sedang & $29-43$ & & 12 & 30,00 \\
& Tinggi & $44-56$ & & 28 & 70,00 \\
\hline Rata-rata & & & & & 45,12 \\
\hline
\end{tabular}

Tabel 2 menunjukkan bahwa sikap responden dalam pengelolaan sampah pada indikator pengurangan termasuk ke dalam kategori tinggi dengan persentase sebesar 62,50 persen. Indikator sikap masyarakat dalam penanganan sampah berada ditingkat tinggi dengan persentase sebesar 70,00 persen. Respon setuju ditunjukkan oleh masyarakat pesisir Kelurahan Srengsem dalam pengurangan dan penanganan sampah, karena beberapa masyarakat sudah mengetahui dan merasakan adanya manfaat dalam mengelola sampah. Sikap dalam pengelolaan sampah yang baik merupakan bentuk tingkat lanjut dari pengetahuan masyarakat yang baik pula untuk mengelola sampah secara berkelanjutan.
Pandangan masyarakat yang baik terhadap pengelolaan muncul karena adanya kesadaran dan dukungan pengetahuan yang tinggi, sejalan dengan penelitian Rahmadani dan Padang (2017) yang menyatakan bahwa sikap seseorang dalam pengelolaan akan timbul apabila terdapat tanggungjawab dan pengetahuan yang besar dari dalam diri individu tersebut untuk menjaga dan memelihara lingkungan sekitar

\section{Tindakan Responden dalam Pengelolaan Sampah}

Tindakan merupakan wujud nyata dari segala aktivitas manusia yang memerlukan praktek atau disebut dengan keterampilan. Tindakan/keterampilan ialah puncak akhir dalam wujud nyata pengelolaan sampah.

Tabel 3.

Tingkat tindakan wanita tani dalam pengelolaan sampah.

\begin{tabular}{|c|c|c|c|c|}
\hline \multirow{2}{*}{$\begin{array}{l}\text { Indikator } \\
\text { Tindakan }\end{array}$} & \multirow[b]{2}{*}{$\underset{\text { kasi }}{\text { Klasifi- }}$} & \multirow{2}{*}{$\begin{array}{c}\text { Interval } \\
\text { kelas } \\
\text { (skor) }\end{array}$} & \multicolumn{2}{|c|}{ Anggota KWT } \\
\hline & & & $\underset{\mathrm{ah}}{\text { Juml }}$ & $(\%)$ \\
\hline \multirow[t]{3}{*}{ Pengurangan } & Rendah & $16-32$ & 5 & 12,50 \\
\hline & Sedang & $33-49$ & 35 & 87,50 \\
\hline & Tinggi & $50-64$ & 0 & 00,00 \\
\hline Rata-rata & & & & 38,03 \\
\hline \multirow[t]{3}{*}{ Penanganan } & Rendah & $14-28$ & 5 & 12,50 \\
\hline & Sedang & $29-43$ & 32 & 80,00 \\
\hline & Tinggi & $44-56$ & 3 & 07,50 \\
\hline Rata-rata & & & & 35,82 \\
\hline
\end{tabular}

Berdasarkan tabel 3 tindakan atau keterampilan responden dalam pengurangan dan penanganan sampah termasuk dalam kategori sedang dengan persentase masingmasing sebesar 87,50 dan 80 persen. Tindakan atau keterampilan masyarakat pesisir dalam mengelola sampah yang terdiri dari pengurangan dan penanganan sampah masih dalam kategori sedang, hal tersebut menunjukkan bahwa tidak semua kegiatan pengelolaan sampah dilakukan secara penuh oleh masyarkat. Tindakan masyarakat masih dalam tahap upaya untuk membiasakan diri untuk mengelola sampah dengan baik dan 
teratur. Pendalaman untuk terampil dalam mengolah sampah baik berbentuk sampah organik dan non organik secara tidak langsung dapat mengembangkan kreatifitas masyarakat dan membuka peluang usaha yang ramah lingkungan (Sari, Lestari, dan Awal, 2018).

Keterampilan sederhana yang biasa dilakukan wanita tani dalam pengelolaan sampah yaitu membuat media tanam menggunakan limbah ruamh tangga baik berupa limbah organik dan non organik sebagai faktor pendukung untuk melaksanakan kegiatan usahatani sayuran dengan memanfaatkan lahan pekarangan dalam program KRPL yang diikuti oleh wanita tani. Sejalan dengan penelitian Lubis, Cahaya dan Paratama (2018) yang menyatakan bahwa dengan bantuan limbah botol plastik bekas air mineral yang disusun dan tata secara teratur dapat menjadi media tanam yang efektif dibandingkan dengan budiaya tanaman yang konvensional

Perilaku masyarakat pada aspek pengetahuan dan sikap menunjukkan tingkat kategori yang tinggi, akan tetapi dalam aspek keterampilan masih dalam tingkat kategori sedang. Hal ini dikarenakan perilaku sejatinya dapat terlihat dari tindakan nyata masyarakat. Ketimpangan yang terjadi antara tingkat pengetahuan dan sikap dengan tingkat tindakan terjadi karena kebiasaan dan tradisi dalam mengelola sampah secara penuh belum dilakukan dalam kurun waktu yang lama, seperti yang dinyatakan oleh Surahma dan Novita (2017) bahwa perilaku dalam mengelola sampah akan berjalan dengan baik dikarena faktor tradisi, kebiasaan, dan faktor lain.

\section{SIMPULAN}

Tingkat perilaku masyarakat pesisir di Kelurahan Srengsem tertuang dalam tiga komponen pembentuk yaitu pengetahuan, sikap dan keterampilan. Tingkat pengetahuan dan sikap masyarakat yang tergolong tinggi akan tetapi belum didukung oleh tindakan atau keterampilan merupakan puncak akhir atau wujud nyata pengeloaan sampah yang sesungguhnya. Pengurangan dan penanganan sampah seperti mengolah limbah menjadi media tanam secara sederhana dan menampung sampah dalam satu wadah agar tidak tertebaran sudah dilakukan oleh wanita tani, akan tetapi masih belum menerapkan secara penuh pengelolaan $3 \mathrm{R}$ dan pemilahan sampah, hal tersebut terjadi karena pegelolaan sampah secara optimal masih belum menjadi kebiasaan.

\section{SANWACANA}

Ucapan terima kasih ditujukan kepada kepada pihak-pihak yang membantu, megarahkan, membimbing dan memberikan masukan dalam pelaksanaan penelitian maupun penyusunan artikel ini.

\section{DAFTAR PUSTAKA}

Abdurahman, D. (2008). Biologi Kelompok Pertanian. PT Grafindo Media Pratama. Badan Pusat Statistik. (2019). Statistik Lingkungan Hidup tahun 2019. https://www.bps.go.id/statistiklingkungan-hidup-indonesia-2019.html Gerungan, W. A. (2004). Psikologi Sosial. Refika Aditama. Bandung.

Gusti, A., Isyandi, B., Bahri, S., dan Afandi, D. (2015). Hubungan pengetahuan, sikap dan intensi perilaku pengelolaan sampah berkelanjutan pada siswa sekolah dasar di kota Padang. Jurnal Dinamika Lingku-ngan Indonesia, 2(2), 100-107.

Listiana, I. (2017). Kapasitas Petani Dalam Penerapan Teknologi Pengendalian Hama Terpadu (Pht) Padi Sawah Di Kelurahan Situgede Kota Bogor. Jurnal Agricia Ektensia, 11(1), 46.

Lubis, R., A. Cahaya, dan R, Pratama. (2018). Pemanfaatan Pekarangan Rumah Dan Limbah Botol Plastik Dengan Metode Tanam Hidroponikdi Rt. 12 Kelurahan Jalan Gedang Kecamatan Gading Cempaka Kota Bengkulu. Jurnal Pengabdian Masyarakat Bumi Raflesia, 1(1). 
Megantoro, D. (2015). Pengaruh Keterampilan , Pengalaman, Kemampuan Sumber Daya Manusia terhadap Usaha Kecil Menengah (Studi Kasus di Panjangrejo, Srihardono, Pundong, Bantul Yogyakarta) Universitas PGRI Yogyakarta.

Notoatmodjo, S. (2011). Ilmu dan Seni Kesehatan Masyarakat. Rineka Cipta. Jakarta

Rangga, K. K., A. Mutolib, H. Yanvika, I. Listiana, dan I. Nurmayasari. (2020). Tingkat Efektifitas Penyuluhan Pertanian di Kecamatan Jati Agung Kabupaten Lampung Selatan. Jurnal Agribisnis Terpadu.

Rahmadani, E., dan Padang, P. K. K. K. (2017). Hubungan Pengetahuan, Sikap dan Ketersediaan Sarana Pengelolaan Sampah dengan Partisipasi Pedagang dalam Pengelolaan Sampah di Pasar Raya Solok Tahun 2017. Skripsi sarjana. Poltekkes Kemenkes Padang Jurusan Kesehatan Lingkungan, Padang.
Sari, M., S. U., Lestari dan R, Awal. (2018). Peningkatan Ketrampilan Mahasiswa Dalam Pengelolaan Sampah Organik Untuk Mewujudkan Green Campus Di Universitas Lancang Kuning. Dinamisia: Jurnal Pengabdian Kepada Masyarakat, 2(2), 193-196.

Setyowati, R., dan S. A, Mulasari. (2013). Pengetahuan dan perilaku ibu rumah tangga dalam pengelolaan sampah plastik. Kesmas: Jurnal Kesehatan Masyarakat Nasional (National Public Health Journal), 7(12), 562-566.

Surahma, M., dan S, Novita. (2017). Pengetahuan, sikap dan pendidikan dengan perilaku pengelolaan sampah di Kelurahan Bener Kecamatan Tegalrejo Yogyakarta. Jurnal medika respati, 12 (2), 74-84.

Teng, H. M. B. A. (2017). Filsafat Kebudayaan Dan Sastra (Dalam Perspektif Sejarah). Jurnal ilmu budaya, 5(1 Juni). 